\title{
IN DEFENSE OF THE MURBURN EXPLANATION FOR AEROBIC RESPIRATION
}

\author{
Kelath Murali Manoj* \\ Satyamjayatu: The Science \& Ethics Foundation, Snehatheeram, Kulappully, Kerala, India
}

The murburn explanation for aerobic respiration was first published at Biomedical Reviews in 2017. Thereafter, via various analytical, theoretical and experimental arguments/evidence published in respected portals over the last three years, my group's works had highlighted the untenable nature of the "electron transport chain (ETC)-driven chemiosmotic rotary ATP synthesis (CRAS) " explicatory paradigm for aerobic respiration. We have also presented strong evidence and arguments supporting the new murburn model of mitochondrial oxidative phosphorylation (mOxPhos). Overlooking the vast majority of our critical dissections, CRAS hypothesis is still advocated by some. Further, queries are posed on the evidence-based murburn explanation without any committed effort to understand the new proposals. Herein, I expose the false attributions made to our works, point out the general and particular flaws/lacunae in the critical attention murburn model received, revisit/dissect the arguments critique(s) floated to support the chemiosmotic proposal, answer the specific queries on murburn explanation and defend/consolidate our proposals for mOxPhos. The current scientific discourse is crucial for correcting major historical errors and finding/founding new concepts of the powering logic and biophysical chemistry of life. Biomed Rev 2020; 31: 135-148

Keywords: bioenergetics; chemiosmosis; proton-motive force; murburn concept; aerobic respiration; mitochondria; oxidative phosphorylation; electron transport chain; trans-membrane potential

The scientists that doubted Peter Mitchell's untenable 'chemiosmosis' and Paul Boyer's flawed 'rotary ATP synthesis' proposals on mitochondrial physiological ATP synthesis lists out as the literal "Who's Who" of mid-20 th century biochemists. Mitchell and Boyer are no more and most of their opponents are also buried in the sands of time. Sadly, Mitchell and Boyer have left behind a coterie of believers that do not seem to budge. It is a sad part of reality that "fait accompli"s exist and it is only the tenacious who can muster the courage and commitment to wage war against the misplaced efforts to maintain an unwarranted status quo. This communication mainly presents the rebuttal to PJS's article in Biophysical Chemistry supporting the chemiosmosis hypothesis (1) and his queries/critique on the murburn explanation for mitochondrial

*Correspondence to: Dr Kelath Murali Manoj, Satyamjayatu: The Science \& Ethics Foundation, Snehatheeram, Kulappully, Shoranur-2 (PO), Kerala, India-679122

E-mail: satyamjayatu@yahoo.com (ORCID: 0000-0003-4515-994X) 
oxidative phosphorylation (mOxPhos) (2-15). Biophysical Chemistry has refused me and my collaborators a platform to present our rebuttals and surprisingly, continues to provide umbrella to the mock 'mOxPhos wars', which is ongoing with another off-shoot of the Mitchell-Boyer paradigm. The murburn proposal was first published in Biomedical Reviews, with cover-page credits (15). In the last edition of this journal, we had stressed on the importance of seeing things differently and cited the matters at stake in the issue (14). Therein, I had also pointed out murburn concept's philosophical impact on our understanding of the origin, sustenance and termination of life (5). Science is the facts and reason based pursuit of seeking out truthful explanations to natural phenomena; and I am convinced that the murburn proposal is supported by its legion of evidence and arguments. Therefore, dauntless, I stand. Starting from a brief overview, I address PJS's defense of chemiosmosis and inputs on the murburn proposal for aerobic respiration (point-wise). Finally, presenting a succinct summation of the untenable aspects of chemiosmosis and salient features of murburn concept, I call for a reorientation of research perspectives in the community.

\section{ON THE CRITIQUE'S APPROACH}

Although objective pursuits must guide a scientist's pursuits, subjectivity/subjectivism is a reality in human endeavors. I point out a couple of aspects on the subjective outlook of my critique's persona. This is not intended to be a personal attack but is a necessary 'evil', to showcase the mettle and outlook of the person who ventures out to undermine our works.

1. Misplaced semantics/logic: PJS's article is titled- "Chemiosmotic misunderstandings", when it should have been "Misunderstandings on/about/regarding chemiosmosis". In his article's highlights section on the journal website, the very first point is incorrectly worded as: "Two controversial proposals regarding chemiosmosis are reviewed." The appropriate articulation could be- "Two critical perspectives on chemiosmosis hypothesis are reviewed." OR/AND "Two alternative explanations for oxidative phosphorylation are reviewed." We point out the above two instances to critically display the inadequacy of articulation at the apologist's quarters, which leads to even more confusions and frustrations at our ends. More importantly, neither have I ever written any 'proposals for chemiosmosis', nor should our ideas/works be deemed 'controversial'. In fact, my works/writings have forthrightly challenged chemiosmosis and this is an honorable (not con- troversial) pursuit in science. Quite simply, we believe that scientific discourse is carried out by "the authority of logic, not by the logic of authority". Just because chemiosmosis is an acclaimed hypothesis, it does not mean that its explanations are accurate. After decades of skeptic study of chemiosmosis, I concluded that it was a fundamentally flawed idea. Only then, I summoned the guts and wits to expose its untenable nature time and again. Scientists must harbor the spirit that hypotheses like chemiosmosis cannot avail immunity or impunity to critical dissections, and deemed sacrosanct forever. If otherwise, we would still have been stuck to a flat firmament, and not roving on a globe! (Further, it must also be remembered that Mitchell was 'ruthlessly' dismissive of his peers' critical inquisitions. So, it is befitting to serve a 'quid pro quo' approach to his ideas/ works and that of his followers' writings. It is unfortunate to note that Mitchell's traditions propagate amongst his followerswhen Mitchell coined the term chemiosmosis, his followers failed to realize the semantic irony that chemiosmosis had little to do with chemistry or osmosis (15).)

2. Non-inclusive/non-comprehensive outlook: In the main text, coming on to the context of our works, PJS writes: "Other criticisms of the possibility of chemiosmosis in aerobic respiration have been put forward by Manoj (28-30)]. The most important arguments seem to be...." My collaborator NM Bazhin is a seasoned biophysical chemist, who had also expressed concerns about the chemiosmotic proposal independently $(16,17)$. He subsequently collaborated with me in pulling down the Mitchellian ideas and establishing murburn concept in bioenergetics realms $(4,18,19)$. Several other diverse concerns were reflected in the writings/calls for 'looking beyond the strictures of chemiosmosis'; made by reputed and independent scientists of the past. To cite a few- Edward Slater, pioneer of bioenergetics and Editor of BBA-Bioenergetics, the flagstaff journal in the field $(20,21)$; Robert Williams, bio-inorganic chemist (Irving-Williams series) (22); Britton Chance, Inventor of stopped-flow enzymology and 'multiscient' (23, 24); Gilbert Ling, electrophysiologist and inventor of Ling-Gerard microelectrode (25); Walter Wainio (pioneer on cytochrome oxidase) (26); and the likes of MJ Nałecz (27), JA Berden (28), L Ernster (29), and several others like Gregorio Weber, Albert Lehninger, David Green, etc. Some of them had staked their credentials to challenge the unrealistic constraints posed by the chemiosmotic rotary ATP synthase (CRAS) paradigm, even after it was recognized with Nobel Prizes in Chemistry $(30,31)$. Over the decades, there have also 
been several other attempts to explain the coupling of NADH oxidation with ADP phosphorylation (32-34). Scientists did not float these alternatives as leisurely artistic expressions, but they did because the subject matter was the crux of life and the 'electron transport chain (ETC)-driven chemiosmotic rotary ATP synthesis (CRAS) proposal was unsatisfactory. Unprejudiced readers can verify the titles and abstracts of the stalwarts' papers cited above and it would vindicate my assertion that I am no wobbly Quixote waging whimsical wars with windmills here (ref. Miguel de Cervantes)! I have published several original papers on various aspects of the mechanism of mOxPhos over the last three years and have two decades' publishing credentials in redox biochemistry. Therefore, I cannot help but wish that PJS should have explored a bit more, before assuring everyone that everything was explained adequately in bioenergetics research and a 'status quo' needs to be maintained, via his maiden manuscript on mOxPhos chemistry.

Further, I see that though PJS's revised communication at Biophysical Chemistry was submitted in June 2020, only three of my critical arguments from my brief critique of CRAS mechanism at the same journal (9) and one dataset alone from our "proof of concept" paper are addressed (13). There is no effort at PJS's end to see that we had comprehensively debunked the "ETC-driven proton pumps generating a proton motive force ( $p m f$; also seen as a trans-membrane potential or TMP), which drives rotary ATP synthesis (RAS)" or "ETC-driven chemiosmotic rotary ATP synthesis (ETC-CRAS)" paradigm. Our effort was commissioned highlighting the multitudes of limitations of individual components and the impossibility of their coming together as a comprehensive whole 'working machine unit' (2-5, 7-15). People are entitled to their beliefs but considering the comprehensive treatment I have offered on the subject with my communications, it would take more than what PJS did for anyone to hold on to the ETC-CRAS view now. We had presented a comparison of 30 point-wise queries and their solutions given by ETC-CRAS and murburn explanations, via an exhaustive invited review (4). Furthermore, we had consolidated the murburn explanation for aerobic respiration by a comparison with the hepatocyte microsomal system (15), accounting for thermogenesis (2), cyanide toxicity (7-9), mitochondrial homeostasis $(4,18)$, explaining overall metabolic purviews $(3,6)$ etc. in diverse journals. This was done using works grounded in both theoretical and experimental arguments, from our group and others' works. Our critical perspective on chemiosmosis and advocacy of murburn explanation encompassed diverse aspects of thermodynamics, kinetics, basic reaction logic, structure-function correlations of proteins, architecture of mitochondria and distribution of components therein, probability/Ockham's razor, predictability, evolutionary principles, etc. Further, murburn concept is an elementary mechanistic idea, as evidenced and established over several years in heme-flavin enzymes redox catalysis and interactions (35-45). The mitochondrial system is just an expanded/ complex heme/flavin proteins' reaction milieu and therefore, it is only natural that the mechanistic principles hold good in this context too. Our mechanistic ideas are also relevant for xenobiotic metabolism (46-50) and dose responses (51). We have also critiqued the ETC-CRAS based explanations for oxygenic photosynthesis and proposed an evidence-based murburn hypothesis in lieu $(19,52-55)$. This is when terms like ETC, chemiosmosis, proton motive force, rotary enzymes, etc. are 'surreal' or 'mirage' like concoctions restricted to the 'entrenched bioenergetics community', solely for explaining the simple phosphoester/phosphoanhydride bond formation in ATP synthesis (14). Therefore, it is ACTUALLY controversial that- (i) the proposal and apologists of chemiosmosis got more than what was due, (ii) our explanations have not yet been cited or addressed or critiqued by even one mainstream mOxPhos researcher, and (iii) PJS makes several false attributions to our works/writings and disowns facts. The few skeptical/ genuine queries that PJS poses regarding murburn concept were already addressed earlier (and are re-explained herein), which shows that our works were not read/comprehended adequately to gain a holistic appreciation or offer substantial critique. Further, PJS's failure to address the crux or breadth of our critique of CRAS explanation indicates that his article is a non-exerted outcome of apologetic pursuits. Therefore, I don't patronize PJS's ideas as "ingenious", as he did for Sunil Nath's usage of Gauss's law for critiquing chemiosmosis (1). If one takes an idea as ingenious, he/she should be on its side and not oppose it. A forthright scientific discourse is conducted by openly critiquing each other's points on which disagreements exist, all the while retaining socially constructive outlooks. By having a competition between two false beliefs and having the real contender pulled out of the ring, the exercise ongoing at Biophysical Chemistry serves only the apologists of CRAS.

\section{POINTS PRESENTED FOR "THE DEFENSE OF CHEMIOSMOSIS" (1)}

Points 'a through c' deals with the issue of the feasibility of harnessing proton pumps within the mitochondrial system. I had pointed out that the low mitochondrial volume $\left(0.2 \mu \mathrm{m}^{3}\right)$ 
and the dissociation constant of water $\left(\sim 10^{-14}\right)$ affords only finger-countable $\left(<10^{1}, \sim 6\right)$ 'free protons' or 'hydronium ions' within the matrix. Therefore, it was conclusively inferred that the miniscule amount of free protons within a mitochondrion cannot serve the purported proton-pumping proteins, which run to $10^{4}-10^{5}(4,12,13,15)$, implying a conservative shortage of $\sim 10^{6}$ free protons in physiological mitochondria. The only way to overcome this predicament is by a hetero- or homo- lysis of matrix water molecules, which requires $>79$ or $>492 \mathrm{~kJ} / \mathrm{mol}$ respectively (18). That alone would not be adequate, as the trans-membrane shipping incurs a cost of $>20 \mathrm{~kJ} / \mathrm{mol}$ (implying a total cost of $\sim 100 \mathrm{~kJ} / \mathrm{mol}$ for outward trans-membrane proton pumping). The Mitchellian calculations show that a complete oxidation of NADH and succinate give 220 and $\sim 150 \mathrm{~kJ} / \mathrm{mol}$ respective overall energetic yield $(56,57)$. Even with an impossible efficiency of $100 \%$, the Mitchellian energetics cannot explain the consistently observed high yields of $\sim 3.5 / \sim 1.9$ ATP molecules per NADH/succinate $(29,58)$, even with the later 'forced consensus' of 2.5 protons per ATP advocated by apologists (59). Further, the 'proton-recycling within a closed mitochondrial pot' purview does not explain the proton deficiency for the chemical reaction of NADH oxidation. This was a charge and mass balancing error that was grossly overlooked in the overall schematics (18). Yet, refusing to see the obvious and elementary flaws, when PJS says that 'water auto-protolysis would afford adequate protons' and 'the energetics of ETC-CRAS is adequate to support proton-pump driven ATP synthesis', it is just a recalcitrant apologist sticking to false claims. We have already addressed the contexts of "proton-hopping or Grotthuss mechanism of proton-pumping", and this is the SAME as the new terminology of "water autoprotolysis" that he uses. If water column was in continuum across the membrane, then there is no directive principle to ensure a gradient across the same membrane. The Mitchellian apologist's convenient "proton is here but not here" (proton is both in and out of the matrix at the same instant!) perception was a 'mirage' sold to the scientific community and it is reiterated that such a perception cannot realistically give a trans-membrane proton gradient. Water auto-protolysis can only give protons for catalysis within the matrix phase and such protons cannot be shipped out without the violation of the fundamental laws of conservation of energy. Further, it is known that most mitochondria and cells work homeostated around the physiological $\mathrm{pH}$ (which is around $\mathrm{pH}$ 7). If a large or small trans-mitochondrial $\mathrm{pH}$ gradient existed, it is a violation of Mitchellian tenets. Furthermore, there is no experimental evidence either that any 'significant workable' $\mathrm{pH}$ gradient exists in real physiology $(23,24)$. The workable $\mathrm{pH}$ gradient has only been demonstrated by an external provision, between cytoplasm and matrix or matrix/outside and not shown in a physiological mitochondrion's matrix and inter-membrane space (IMS). The proton-equilibration between IMS and cytoplasm in eukaryotes (or the equilibration of periplasmic milieu with external medium for prokaryotes) (12) clearly shows that the qualitative idea of "crowding of pumped out protons in the IMS" is just a mirage advocated by Mitchell (15). We have also explained clearly why we observe a higher rate of equilibrium driven ATP synthesis in some experimental setups (as exemplified the misunderstood Jagendorf experiment, which was erroneously taken by all as a support for Mitchell's proposals) $(4,12,13,18)$. This resulted because of a lopsided view of the steady-state chemistry. Very importantly, how can the proton-centric explanations explain ATP synthesis in alkalophilic bacteria? PJS should read our works fully and try to understand our criticisms first, and to aid this process, I take extra space in Figure 1 to drive home the crucial points, which seems to have escaped the skeptical outlooks of scientists.

The falsities of Mitchellian ideas are exposed already through the analysis of both standing and steady-state considerations $(12,15)$. The flaw in the ETC-CRAS energetics calculation becomes even more blatantly evident when one sees that the ETC scheme advocates a multi-step single/two electron transfer process wherein the energetic window of any single ET process at the Complexes like I or III are unviable to afford the desired outcomes $(4,12,13)$. Therefore, when PJS says in this context that- "no sources for the values of protons pumped were given" in my article, it is a false attribution. We have credited the relevant sources and the calculations of energy yields at each step can be verified by unbiased individuals. Further, PJS says that his calculations show new support for Complex-based pumps, but there are none at all that address my concerns and he sticks on to the same erroneous equations and faulty thermodynamic assumptions. (I shall write more about this in a subsequent section.) In contrast, our critical analyses have exposed erroneous assumptions (with respect to the mechanism of electron transfer and energetic drives) in a bevy of heme/flavin redox catalytic systems $(35-45,51)$, hepatocyte microsomal membrane interfacial system involved in xenobiotic metabolism (46-50) and also in light-sponsored ATP-synthesis in chloroplasts (19, 52-55). 


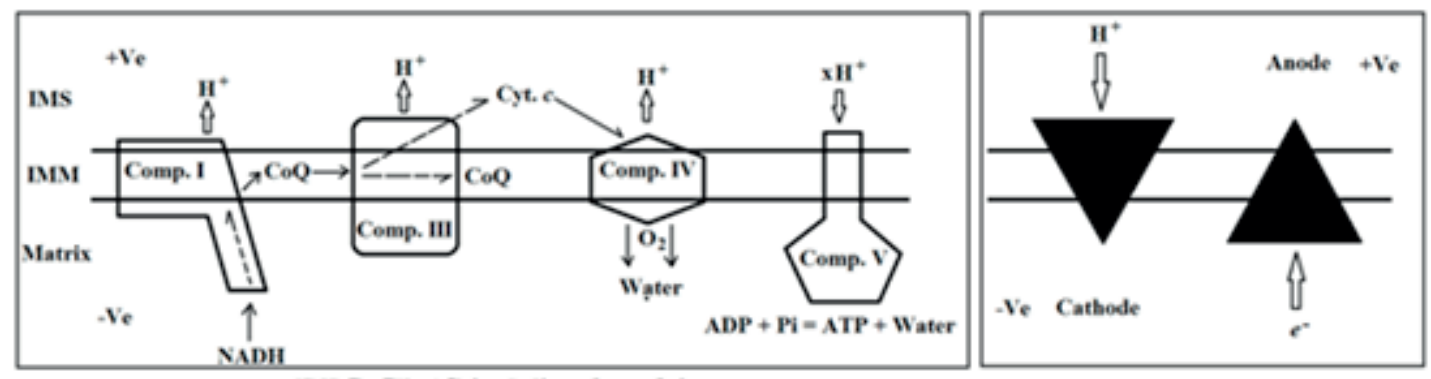

ETC-CRAS in Mitochondria

Workable electrochemical system

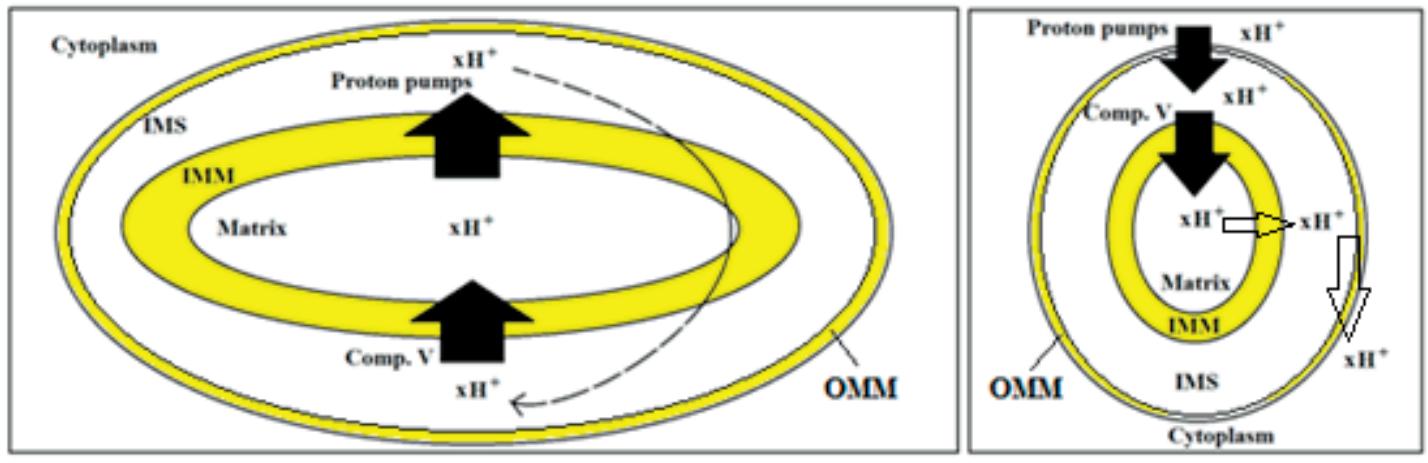

Proton motive force and rotary ATP synthesis

Workable pump-motor connectivity

Figure 1. A comparison of the electrical (top panels) and mechanical (bottom panels) purviews of the unrealistic ETC-CRAS proposal with realistic working models. A steady-state working model of electrical system wherein a polarity is maintained across a membrane allows only directional flow of positive or negative charges (top-right panel). However, the ETC-CRAS scheme seeks a deterministic 'flow/transfer' of one or two electrons against gradients and against polarities (top-left panel). Pumps work directionally in an open system and the flow can be used to work only in a disconnected phase. For example, protons can be pumped (or enter spontaneously) into the IMS phase and they could enter matrix phase via Complex $V$ and such a system could be viable in steady-state as long as directional exits also existed (bottom right panel). However, the CRAS proposal seeks the recycling of protons within the IMS and matrix phases, working across the very same inner mitochondrial membrane (bottom left panel). Clearly, the ETC-CRAS model is a violation of basic notions of workable machine logic. Therefore, the electro-mechanical ETC-CRAS model of ATP synthesis is untenable.

Point ' $d$ ' deals with the arrangement of redox centers in the structure of Complex I. For explaining the irregularity that redox potentials of the various Fe-S centers are not arranged along a desired linear order in the long arm of Complex I, PJS uses the Marcus theory terminologies of reorganization energy, endergonicity and packing density of atoms, etc. to obfuscate the reader. Quite simply, when two redox centers are present in a string too far apart and there is an unfavorable gradient between them, electron transfer could occur; but this would incur heavy energetic costs. The proteins are not sitting there as a source for this energy by mere 'repeated relaxation' of their atoms or structures. However, PJS does not touch upon the more serious aspects of why exactly should the Complex I have such a protruded matrix-arm that is significantly discon- nected from the proton-pumping trans-membrane foot, why at all should there be so many one-electron centers therein, why should some of the redox centers lie outside the electron transfer route and why should some redox centers be accessible to solvent and why should the arm have multiple ADP binding sites, etc.. This is besides the multitudes of other structure-function correlation and mechanistic flaws we had highlighted regarding the ETC-CRAS perspective, in that very paper (3) and others $(4,13,15)$. Clearly, PJS has undertaken only a non-committal defense of the ETC-CRAS explanation, and such an effort does not serve genuine scientists' curiosity and does not inspire the skeptics to dig deeper.

$\underline{\text { Point 'e' deals with the reversibility of Complex V mediated }}$ 
function of ATP synthesis. PJS uses affirmations of faith and earlier refuted arguments to restate his belief that Complex V can synthesize ATP in physiological steady-state conditions. We have repeatedly pointed out why equilibrium driven ATP synthesis within the in vitro systems CANNOT be correlated to physiological conditions $(4,13)$ and also explained why Complexes I through IV are the real ATP-synthases of physiology. The murburn perspective is that Complex V aids ATP synthesis by inletting protons, which help 'package' semi-reacted intermediates and this attribution is justified by all structural and functional awareness known of the Complex multimeric protein. If thermodynamics and kinetics have any meaning and relevance in explaining reaction chemistry mechanisms, PJS should critique our exhaustive demonstrations of how equilibrium driven ATP synthesis by the equations that he/ Mitchell/Boyer uses can only give pM to nM levels ATP in mitochondria within steady state conditions (4). PJS should address the simple predicament- why should Complex V have about ten million fold higher affinity for ATP compared to ADP and not accord false attribution to our works by saying that we have made unsubstantiated claims in this regard. I quote verbatim select contents of a section titled "ATP is stabilized relative to $A D P$ on surface of $F_{1}$ " from the revered textbook, Lehninger: Principles of Biochemistry (Chapter 19, page 709, left column, paragraph 3) (56) that many of us have perused for long, as professors and professionals of Biochemistry-

"ATP synthase stabilizes ATP relative to ADP + Pi by binding ATP more tightly, releasing enough energy to counterbalance the cost of making ATP. Careful measurements of the binding constants show that FoF1 binds ATP with very high affinity $\left(K_{d} \leq 10^{-12} \mathrm{M}\right)$ and $A D P$ with much lower affinity $\left(K_{d}\right.$ $\left.\approx 10^{-5} \mathrm{M}\right)$."

By now, it should be evident to any unprejudiced reader as to who is making unsubstantiated statements and false attributions here!

\section{ANSWERING THE QUERIES/INPUTS (1) ON THE MURBURN MODEL OF MOXPHOS}

PJS starts off by the false attribution that murburn scheme considers 'mitochondrial ETC' as a source of diffusible reactive oxygen species (DROS). I have called out against the usage of redundant terms such as ETC, proton motive force, etc $(9,12,14)$. It evades me how PJS does not see that murburn explanation deems Complexes I through IV as independent agents for harnessing the reactivity of DROS for ATP synthesis, and this cannot be seen as an extension or endorsement of the erroneous ETC concept. Further, he critiques the protocols adopted and results obtained in our preliminary studies (13) and dismisses them as artifacts. The discerning reader must note that PJS does not cite our subsequent meticulous works with HPLC employing elaborate controls, which reproduced the results of our earlier studies and extended them to ratify the proposals with probes for cyanide inhibition (11). This attitude cannot be appreciated or respected. Very importantly, PJS is silent on the earlier experimental reports by various other pioneering researchers like Cohn/Drysdale (60), Galina Mironova (61), Tyszkiewicz/Roux (62), Kathleen Mailer (63), etc. that we have cited, which confirm ROS-assisted ATP synthesis in mitochondria and chloroplasts. Unfortunately, he chooses not to see such works or the myriads of theoretical and experimental supports from our own and others' papers, which we have cited to bolster the murburn explanation of mOxPhos $(2-15,18)$. Most importantly, murburn explanation is the only standing rationale for cyanide toxicity towards several cellular physiologies $(7,8,43-45)$. A biochemical mechanism is ratified by its potency to explain inhibitions and the murburn theory explains the outcomes of mitochondrial toxic principles of vitamin A, rotenone, oligomycin, venturicidin, bongkrekate, etc. and a bevy of interfacial uncouplers $(4,12)$ whereas Mitchellian proposal falls flat. Therefore, PJS's brief critical attention given to the murburn theory of mOxPhos does not afflict any dents on its edifice or citadel. His treatment of our arguments on the 'non-obligatorily required status' of Complex $\mathrm{V}$ in diverse single-celled organisms is addressed in an unconvincing manner. The argument that certain facultative anaerobic organisms/cells could make ATP via glycolysis and recycle nicotinamide nucleotide via fermentation is flaky, as it is not relevant for aerobic organisms living at adequate oxygen levels, wherein the experiments were conducted. Further, the high energy requirements and dynamic ATP turnovers for the organisms (we cited) to survive and grow cannot be met with the inefficient metabolic schemes PJS quotes. Therefore, our argument on the dispensability of Complex V stands. Furthermore, our theory is also bolstered by the COMPLETE absence of mitochondrial Complexes I, III \& IV (the purported proton pumps of Mitchellian theory) in the hypoxic growth conditions of the newly discovered cnidarian, Henneguya (64). The fact that it can synthesize ATP with Complex II \& V can be explained by murburn concept (18). Even though we have already addressed key cynical queries like the ones PJS posed on the relevance of murburn concept within the contexts of 
evolution/divergence of various cellular physiologies $(4,13$, 18), I address the two specific points he raised below.

1. Why would a membrane-bound system be invariably necessary for coupling reduction of the external electron acceptor to ATP synthesis if only oxygen radicals were needed to power ADP phosphorylation?

We have explained clearly that the reaction must occur at the phospholipid interface to enhance the yields, and is further enabled by a closure of the microcosm (lowering free protons to stabilize radicals) and the multiple one-electron redox centers within the membrane-embedded proteins are a testament to our theory (2-15). We have already explained such facets in the relatively simpler heme proteins, like cytochrome P450 mediated catalysis (35-51). For example, we showed that incorporation of low amounts of fatty acyl substituted/ functionalized vitamin $\mathrm{C}$ diverted the DROS in milieu and inhibited the reaction outcomes (a contrast to the negligible effects seen with even higher amounts of the soluble vitamin C). Vice versa, low amounts of vitamin E inhibited the reaction but even higher amounts of its soluble derivative of Trolox did not significantly perturb the reaction. Similar outcomes were noted by incorporation of soluble DROS modulating enzymes vis a vis membrane-lodged DROS modulating enzyme. I don't understand why PJS did not take note of the experiments we suggested (4) to ratify the murburn predictions as a challenge. These experiments predict a gradual increase in efficiency of the DROS-aided ADP phosphorylations in reductionist setups, thereby potentially validating the murburn theory. Quite simply, PJS's obliviousness is not to our disadvantage, but his. Unfortunately, it is he who gets the platform to pervade the status quo and we are not permitted to defend our meticulous works and meritorious ideas!

2. If ATP synthesis were performed through the intervention of ROS, how could oxidative phosphorylation be performed during anaerobic respiration and different growth yields from the same nutrient be obtained only by changing the oxidation state of the respiratory acceptor? If "murburn" scheme were correct, it would imply that those (earliest phototrophic organisms) would have been incapable of converting light energy into ATP and therefore their light-sensitive reaction centers would only provide excited electrons for the generation of NADH/NADPH, requiring those organisms to obtain the ATP necessary to fixate $\mathrm{CO}_{2}$ through other means. (The spirit of this query resonates in some later sentences on chemo-autotrophs.)
While oxygen-centered radicals and ions feature in aerobic systems, other ions/radicals (based in N, S, Fe, etc.) could feature in the anaerobic/anoxic systems $(4,18)$. Also, enzymes such as nitrate reductase possess heme and FeS clusters and can work in a manner which is analogous to mitochondrial oxygendependent respiration. In this regard, our theory explains the higher efficacy, diversity and growth rates of oxygenic metabolic systems. Oxygen has direct equilibrium with water and gives $\mathrm{CO}_{2}$ as the primary product, which can be easily voided and it also provides a facile homeostatic machine logic (18). The one-electron route for synthesis of energy currency goes via the simple cycle of "oxygen - superoxide - peroxide - hydroxyl radical - hydroxide ion - water", and it can be easily visualized under this view why addition of external protons/ gradients enables enhanced ATP synthesis in physiological setups. (Even with pure Complex V, one would expect the same outcome as the reactants ADP and Pi would need protons at the physiological $\mathrm{pH}$ to make ATP and water.) Murburn paradigm is consistent with the employment of diverse metal centers in various metabolic and physiological routines of archaeobacteria, anaerobic micro-organisms and prokaryotes. The transition from various inorganic ionic/radical species to oxygen-centered ionic/radical species is also chemically consistent with the murburn theory but inconsistent with purely affinity-based or structure-based electron transfers. While the ETC-CRAS explanation is definitely "irreducibly complex" (ref. Michael Behe), murburn theory is a simple and evolvable system of molecules, ions and radicals that can be envisaged to work spontaneously in heterogeneous or homogeneous phases. Since PJS speaks of 'intellectual parsimony', I must remind him that it is murburn concept that fits the bill, not ETC-CRAS. I urge the readers to see Table 1's point 4 for a simple comparison. Therefore, the murburn proposal provides a powerful molecular mechanistic scaffold for the evolution of metabolism-based powering logic of life. It is currently the only theory that explains ow respiratory metabolism is connected to thermogenesis/homeostasis and why oxygen became the major elixir for life along with the solvent of water, and why the phosopholipid membrane became a vital cell-component (18).

\section{ON THE CLAIMS OF NEW CALCULATIONS SUPPORTING CHEMIOSMOSIS (1)}

We had exposed the falsity of the so-called improved/simplified Mitchellian equation that PJS quotes in the beginning of his paper's equation $1: \Delta \mathrm{p}=\Delta \mathrm{E}-(\mathrm{RT} / \mathrm{F}) \log \Delta \mathrm{pH}$ (1). In 
literary terms, equation 1 connotes that the net proton motive force ( $\Delta \mathrm{p}$; usable energy for ATP synthesis) is a sum of trans-membrane electrical potential/field $(\Delta \mathrm{E})$ and a protonconcentration gradient term $(\sim 0.06 \Delta \mathrm{pH})$. The reader must understand that the Mitchellian equation for proton motive force has no foundation in reality or in holistic thermodynamic accounting because: (i) Outward proton-pumping activity from matrix cannot conserve energy on IMS protons and use them to work for ATP synthesis using an inward flow across the same membrane, back into the same phase. \& (ii) Even if the energy is conserved, we had showed that for physiological conditions that entails a nett $\Delta \mathrm{p}$ of the observed $\sim 0.2 \mathrm{~V}, \mathrm{a} \Delta \mathrm{pH}$ term of $0.03 \mathrm{~V}$ is supposed to generate a $0.17 \mathrm{~V}$ equivalent of trans-membrane electrical field component (4). This is equivalent to a banking statement as follows: I withdrew 30 dollars from my savings account, and Mitchell Bank's teller blessed the whole transaction with a 200 dollar credit entry into my checkings account! For those that did not understand this treatment or analogy, I urge once again to read our earlier works or/and see Figure 1 and Table 1, so that the fallacies and mirages of ETC-CRAS can be understood from simpler perspectives. Even if we accede to Mitchellian proposal, there is no way that any electrostatic energy conserved in protons or their trans-membrane flow via Complex V can afford ATP synthesis via a two-electron reaction scheme. ATP synthesis is a simple chemical reaction, not some unseen and unheard electromagnetic stunts that only mitochondria and chloroplasts can achieve. It is IMPOSSIBLE to accept that the same agent of Complex V can act whimsically to both make and break ATP in physiology! Further, the CRAS model's unbalanced equations (equations 12,13 of PJS's paper) are inappropriate to account for explaining the coupling of NADH oxidation with steadystate ATP synthesis within mitochondria $(4,13)$. Further, there is no way equation 1 can couple with the equations $12 / 13$ in reality and therefore, there is no real explanation afforded by ETC-CRAS. There is nothing called 'proton motive force (pmf)' outside the realm of bioenergetics and it exists in this field only because of faulty assumptions and misplaced observations taken as experimental supports. Outward pumping of non-existing protons by non-existing pumps cannot magically conserve energy on the projected IMS protons. Further, there is no electro-mechanical way to use the protons for ATPsynthesis using a cyclic flow across the same membrane. In simulated systems, when external proton gradients are given, ATP synthesis is facilitated due to an equilibrium-driven reaction, which cannot be operative in mitochondrial physi- ology. Most physiological bioenergetic systems are known to work with little $\mathrm{pH}$ gradient, whereas Mitchell's proposal originally sought large $\mathrm{pH}$ gradients of several units across the inner mitochondrial membrane. Accounting for the lack of an observable large $\mathrm{pH}$ gradient by conveniently adding a large electrical term is unjustifiable, as it creates energy from nowhere! The mitochondria are proton deficient systems that work with oxygen-centered radicals and ions, and the reaction needs protons for neutralization, to form $\mathrm{O}-\mathrm{H}$ bonds. This is particularly the case when starting with NADH, as it gives two electrons but only one proton. The way life uses this molecule is a wonderful thermodynamic feat. Protons contribute a large $\Delta_{\mathrm{f}} G^{\prime \mathrm{O}}$ aq of $452 \mathrm{~kJ} / \mathrm{mol}$ and this was overlooked by all in the field. So, when NADH gets oxidized and DROS form and they attack $\mathrm{ATP}+\mathrm{Pi}$, the formation of $\mathrm{O}-\mathrm{H}$ bonds in peroxide, water, quinols, etc. drive the equilibrium to the right. This is the physiological coupling reaction. Even in the simulated equilibrium-driven ATP-synthesis by Complex V (ADP + Pi $+\mathrm{H}^{+} \rightarrow$ ATP $\left.+\mathrm{H}_{2} \mathrm{O}\right)$ in vesicles, the reaction would need a cytoplasmic proton for effective ester bond formation within the closed/aprotic mitochondrial matrix. Therefore, providing a proton gradient (as in the famed Jagendorf's experiment) gives enhanced ATP formation, and this has no bearing with any 'pmf'. The one-electron route for synthesis of energy currency goes via the simple cycle of "oxygen - superoxide - peroxide hydroxyl radical - hydroxide ion - water", and it can be easily visualized under this view why addition of external protons/ gradients enables enhanced ATP synthesis in physiological setups. Murburn paradigm is consistent with the employment of diverse metal centers in various metabolic and physiological routines of archaeobacteria, anaerobic micro-organisms and prokaryotes. It is highly unbecoming of any professional to disregard the thermodynamic and kinetic arguments/evidence we have already presented in this regard. Again: it is the formation of oxygen-centered radicals/ions and their reactions with $\mathrm{ADP}+\mathrm{Pi}$ that lead to TMP and it is not the TMP which leads to ATP-synthesis. We have provided the theoretical basis and the experimental evidence for these assertions (2-19). When one says TMP drives ATP-synthesis, it is like saying that the cart drives the horse! Since both Mitchell-Boyer's CRAS and Sunil Nath's two-ion torsional ATP synthesis (TITAS) proposals rely on the ETC concept and see Complex V as the physiological ATP synthase (and deem DROS as toxic wastes), they are very similar in key perspectives and differ only marginally $(4,9)$. Therefore, the marginal details are insignificant with respect to the bigger picture. The realities above render the major part of 
PJS's write-up and his ongoing debate with Sunil Nath at Biophysical Chemistry redundant, as it must be seen as a sparring between two misplaced perceptions. In this context, I would like to apprise the editor/readers that my dissection of Sunil Nath's defense of TITAS and attack on murburn explanation is published in Biomolecular Concepts (10).

Table 1. A comparison of the ETC-Chemiosmosis-Rotary ATP synthesis and murburn paradigms for mitochondrial oxidative phosphorylation

\begin{tabular}{|c|c|c|c|}
\hline No. & Criteria & The incumbent murburn paradigm & The discredited ETC-CRAS model \\
\hline 1 & $\begin{array}{l}\text { The interactive roles } \\
\text { of } \mathrm{O}_{2} \text { and inhibition } \\
\text { by cyanide. }\end{array}$ & $\begin{array}{l}\text { DROS sponsors ADP phosphorylation in vitro and } \\
\text { in vivo; Complexes I through IV have ADP-binding } \\
\text { sites and several 1e- redox centers; DROS produced } \\
\text { is proportional to NADH/succinate and } \mathrm{O}_{2} \text { provided; } \\
\text { explains cyanide toxicity. }\end{array}$ & $\begin{array}{l}\text { Cannot reason multiple } 1 \mathrm{e}^{-} \text {redox centers and } \\
\text { formation of DROS; fails to explain reaction } \\
\text { viability/kinetics; incompatible with the } \\
\text { requirement, mobility and reactivity of } \mathrm{O}_{2} ; \\
\text { cannot explain acute toxicity of cyanide. }\end{array}$ \\
\hline 2 & $\begin{array}{l}\text { The relevance of } \\
\text { pH and the roles of } \\
\text { protons }\left(\mathrm{H}^{+} / \mathrm{H}_{3} \mathrm{O}^{+}\right)\end{array}$ & $\begin{array}{l}\text { mOxPhos is feasible at physiological pH without } \\
\text { gradients; reasons proton gradient driven equilibrium } \\
\text { synthesis in vitro and in vivo owing to the large value } \\
\text { of } \Delta \mathrm{G} \text { of formation of protons (sourced from cytoplasm, } \\
\text { not IMS); interfacial proton dynamics explains } \\
\text { uncouplers' effects. }\end{array}$ & $\begin{array}{l}\text { The free protons in mitochondrion is }<10^{1} \\
\text { whereas purported proton pumping ETC } \\
\text { proteins are }>10^{5} \text {; fails to explain how or why } \\
\text { supplying a proton gradient gives higher ATP } \\
\text { synthesis in vitro or in situ; uncouplers' action is } \\
\text { inexplicable. }\end{array}$ \\
\hline 3 & $\begin{array}{l}\text { The coupling and } \\
\text { control of reactions, } \\
\text { non-integral and } \\
\text { variable reaction } \\
\text { stoichiometry, } \\
\text { TMP and overall } \\
\text { thermodynamic } \\
\text { grounding and } \\
\text { efficiency of reactions, } \\
\text { etc. }\end{array}$ & $\begin{array}{l}\text { A single pot continuous fed-batch reaction system } \\
\text { within a proton-limited environment explains TMP } \\
\text { generation; TMP is proportional to DROS; the equations } \\
\text { for ATP synthesis are grounded in thermodynamics, } \\
\text { explaining the yields and efficiency; provides a } \\
\text { direct chemical coupling logic and thermodynamic } \\
\text { pull control logic to explain the increase in oxygen } \\
\text { consumption with presentation of ADP+Pi; stochastic/ } \\
\text { statistical scheme explains variability across labs. }\end{array}$ & $\begin{array}{l}\text { A deterministic mechano-electrical stunt of a } \\
\text { series of 2e reactions with bi-directional and } \\
\text { simultaneous transport of charges within a } \\
\text { 'closed pot' cannot give useful work; fails to } \\
\text { explain the origin/harnessing of TMP; cannot } \\
\text { reason the high efficiency or overall variability } \\
\text { of reaction stoichiometry; fails to provide a } \\
\text { tangible coupling logic for NADH oxidation and } \\
\text { oxygen reduction with ADP phosphorylation; } \\
\text { violates fundamental laws of thermodynamics. }\end{array}$ \\
\hline 4 & $\begin{array}{l}\text { What are the minimal } \\
\text { reaction components } \\
\text { required? Does } \\
\text { the mechanism } \\
\text { qualify for Michael } \\
\text { Behe's "irreducible } \\
\text { complexity"? }\end{array}$ & 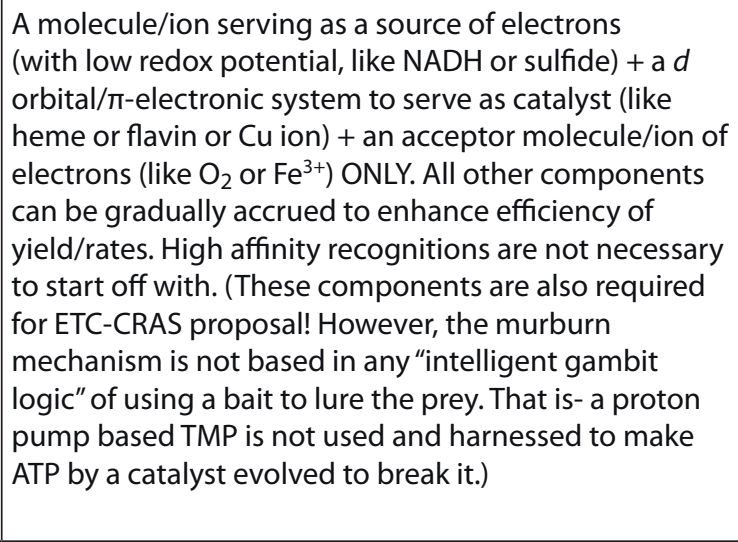 & $\begin{array}{l}\text { A bevy of electron donor and acceptor } \\
\text { proteins/molecules embedded in a closed } \\
\text { phospholipid membrane, which is in turn } \\
\text { enclosed in yet another membrane + electron } \\
\text { transfer catalysts working in intricately woven } \\
\text { deterministic pathways recognizing each other } \\
\text { with topological affinity + proteins that can } \\
\text { couple electron transfer to trans-membrane } \\
\text { proton pumping and TMP generation + 'high } \\
\text { concentration of protons in' to serve proton } \\
\text { pumps AND the exclusive option of 'low protons } \\
\text { in' for generating TMP + molecular motors } \\
\text { triggered by protons/TMP, etc. and more...... } \\
\text { Definitely, irreducibly complex! }\end{array}$ \\
\hline 5 & $\begin{array}{l}\text { What is the least } \\
\text { appealing facet of } \\
\text { the mechanistic } \\
\text { proposal? }\end{array}$ & $\begin{array}{l}\text { DROS are considered toxic and wasteful metabolic } \\
\text { manifestations. They are deemed as agents of chaos } \\
\text { by the research community. This concern is merely an } \\
\text { aesthetic perspective. }\end{array}$ & $\begin{array}{l}\text { The same agent of Comp. V makes and breaks } \\
\text { ATP in mitochondria. For this, either Comp. } \\
\text { V must have supramolecular intelligence or } \\
\text { mitochondria must 'weave magic'. }\end{array}$ \\
\hline 6 & $\begin{array}{l}\text { Is the mechanism } \\
\text { relevant across other } \\
\text { redox metabolic } \\
\text { systems? }\end{array}$ & $\begin{array}{l}\text { Explains reaction kinetics and mechanism of heme/ } \\
\text { flavin proteins, reasons fundamental physiologies } \\
\text { of maverick dose responses, thermogenesis and } \\
\text { xenobiotic metabolism in the cytoplasmic microsomal } \\
\text { system, thermogenesis with uncoupling proteins, } \\
\text { photophosphorylation, etc. Therefore, the reaction } \\
\text { logic is ubiquitous. }\end{array}$ & $\begin{array}{l}\text { Since TMP is not involved in microsomal } \\
\text { systems, its mechanistic principles of } \\
\text { uncoupling are false. Dissipation of TMP } \\
\text { cannot be a viable reason for thermogenesis } \\
\text { in normal or adipose tissues. The mechanistic } \\
\text { terminology is only heard of within the realm of } \\
\text { bioenergetics. }\end{array}$ \\
\hline
\end{tabular}




\section{SUMMATING THE CURRENT STATUS AND PROJECTING THE FATE OF AFFAIRS}

We have already presented an overview of the differences between the chemiosmotic and murburn paradigms and offered comparisons of several specific and holistic perspectives of the two models of mOxPhos in our earlier publications $(4,13$, 15). However, for the readers' immediate convenience, via Table 1 \& Figure 1, I have presented the key evidence and arguments regarding ETC-CRAS and murburn proposals of mOxPhos. The definitive comparisons in Table 1 and the visual perspectives and comparisons given in Figure 1 should enable a discerning reader to decide independently on the meritorious/ competitive option among the two.

When PJS writes (1): "It (chemiomsosis) may eventually be found wanting, but parsimony and intellectual humility should force us to postpone its replacement to postpone its replacement to a moment when enough shortcomings have been found and a novel paradigm which offers as much explanatory power is ready", the confusions and worries among the entrenched coterie can be well understood by a discerning individual. For, if not for cognitive bias/dissonance, PJS would have registered the fact that chemiosmosis is out of the 'game' already and murburn paradigm is a competitive alternative for further explorations in the field. The word 'chemiosmosis' itself was a semantic misadventure, as this surreal proposal has nothing to do with chemistry or osmosis $(12,14,15)$. Gauging by the extent of corrections made in the original proposal over time, it is evident that even the apologists of chemiosmosis did not have any idea about it and just kept on changing the cloak as flaws were realized. Currently, it sustains in academia merely by the consensus among an entrenched lot. I had serious doubts against the proposal even as an undergraduate student and as a Professor, some of my students also have expressed dissatisfaction with it. I can also affirm that two distinct and unaffiliated seasoned authors of leading textbooks on Bioenergetics and Photosynthesis have communicated to me their 'shaky beliefs' in Mitchellian postulates. Mitchell had proposed the proton concentration gradient as the driving principle (based on whim, or perhaps, saw some analogy with an acid battery) and when it was seen that this was grossly inadequate energetically, an electrical potential term was added to compensate. Similarly, Paul Boyer had also advocated phosphohistidine as the enzyme-linked phosphorylating intermediate, before coming to RAS proposal $(12,15)$. Though not a shred of evidence existed to support Mitchell's or Boyer's ideas, their 'fantastic' ideas gained roots only because the murburn reaction chemistry logic evaded the frustrated and disoriented researchers. The research community in the field had tried and tired, failing to explain the fundamental powering logic of life for decades. This in turn, was because the misperceptions of the existence of an ETC and misattribution of Complex V as the physiological ATP synthase carrying out "active-site phosphorylation". The unfortunate experiments of Jagendorf and Racker and their misinterpretations only achieved a fait accompi. Today, with the option of murburn concept, we need not pay 'bon homie' to any pied pipers (ref. Robert Browning) as our flocks could be led astray. Continuing the 'status quo' would be at the expense of the vast majority of our younger researchers starting out their careers! What about the professorial guilt of teaching one's students the misplaced tenets of chemiosmosis? It is indeed just a matter of time that teachers would find themselves at an utter loss, facing their students' fundamental queries in interactive sessions. As internet-based social media allows the facile permeation of information, the realities cannot stay bottled for long. There would be enough enthused kids around the block to amuse themselves and mock the emperor; and professors shouldn't be swayed by the weavers anymore (ref. Hans Christian Anderson). More importantly, what about science being the philosophy and practice of pursuit of truth, and one that builds on the known and the available? For carrying on with chemiosmosis, one must not only jettison the most beautiful ideas known- thermodynamics, fundamentals of enzyme catalysis, basic awareness on reaction chemistry, etc., but also disregard the meticulous and valuable information made available by researchers who have worked tirelessly to reveal facts on mitochondrial composition/physiology. Further, invaluable man-hours, resources and finances are wasted daily to uphold the ETC-CRAS paradigm. Clinical data continue to be misinterpreted through the defective deflections of chemiosmosis (14). This is when millions of people continue to suffer owing to poorly understood health ailments. By reorienting perceptions on DROS within the medical research community (6), countless lives can be saved and we could also avail new avenues to channelize several ancient traditional practices into mainstream scientific understanding $(3,13)$.

Via our earlier works, we have comprehensively discredited the fundamental assumptions of ETC-CRAS beyond reasonable doubts and explained the purported evidence/arguments for ETC-CRAS with well-grounded quantitative/qualitative logic. Therefore, it is imperative that the ETC-CRAS explanation is discontinued and murburn theory is seen as a viable alternative. As of now, we know of no data or suppositions 
that violate the murburn perspective and I believe that if any findings so arise, even murburn theory must be discarded. Until then, the incumbent murburn theory is poised to offer significant insights into several metabolic and physiological processes, and provide a profound understanding of life, per se. For, the fabric of life is made of molecules and ions. Radicals are the long-missed missing links, the dynamic and transient matter offering the connectivity for electron transfers and bond formation around/at the lipid interface, thereby linking a wide variety of metabolic and electrophysiological transduction phenomena. If NO (nitric oxide) could evolve to carry out the delicate task of serving as a specific cellular messenger, why cannot other radicals serve as agents for lifesustaining processes? The critical foundations of time-tested thermodynamics, kinetics, probability, and Ockham's razor must prevail over traditional aesthetics/consensus and guide us in rational pursuits. All natural phenomena in other scientific streams are explained by the principles above and terms like chemiosmosis and proton motive force are not seen anywhere; these cannot be allowed to "stick out as an irreducibly complex sore lump", mocking the principles of evolutionary biology. I reckon that scientists the world over should hearken to my forthright beckon; and seize the moment and the opportunities that the situation presents. As of December 2020, I have now disseminated several more documents for the scientific community, advancing murburn concept's relevance in various life processes: involvement of quinones in bioenergetic routines $(65,66)$ ), roles of small redox proteins in mitochondria and endoplasmic reticulum (67), thermodynamics/reaction chemistry of xenobiotic metabolism, mitochondrial oxidative phosphorylation and photophosphorylation $(18,19,68)$, the modality of light's interaction with pigments in chloroplasts and roles of thylakoid membranes in the process $(69,70)$, cellular redox homeostasis (71), signal transduction and processing of signals in the photoreceptive processes at human retina (72), etc.

To conclude, it would have served all if the apologist/critique had bothered to appraise himself on the chronological variations in the 'consensus' values of protons pumped by each of the mitochondrial respiratory complexes. Then, perhaps, he would have seen how the advocates and apologists shifted shapes/ideas over the last six decades on the most fundamental aspects of the ETC-CRAS proposal. I express deep angst at the inadequate care apologists exhibit by making false attributions to our works; although I do appreciate anyone's critical attention and civil tones used for the discourse. However, we aren't saints and we cannot retain a very pleasant disposition, when a critique indulges in subversive misadventures and repeatedly writes to Editors of our published manuscripts, making false attributions about our works! I would like to caution all that science mandates the authority of logic, not the logic of authority. Using an establishment to further an entrenched perspective with subversive tactics SHALL NOT be achieved at the expense of facts, reason and constructive purpose. We are in the long haul here, and we are sporting: Love all, let's serve, and bring it on!

I am immensely indebted to editors of Biomedical Reviews for publishing this rebuttal (and further inputs in this regard), after the editorial leadership and process of Biophysical Chemistry did not permit me or my group members to present rebuttals to the murburn concept's criticism at their portal. A Supplementary Information file is submitted to Biomedical Reviews, representing the visual evidence supporting my claim that (i) CRAS proposal has only resulted in 'failed consensus-making exercises', and (ii) PJS made several false attributions against my (group's) writings. This can also be made available to any critical minded reader at the author's website or via email.

\section{REFERENCES}

1. Silva PJ. Chemiosmotic misunderstandings. Biophys Chem 2020; 264: 106424. [DOI: 10.1016/j.bpc.2020.106424]

2. Manoj KM, Gideon D, Jacob V. Murburn scheme for mitochondrial thermogenesis. Biomed Rev 2018; 29: 73-82. [DOI: 10.14748/bmr.v29.5852]

3. Manoj KM. The ubiquitous biochemical logic of murburn concept. Biomed Rev 2018; 29: 89-97. [DOI: 10.14748/ bmr.v29.5854]

4. Manoj KM, Soman V, David Jacob V, Parashar A, Gideon DA, Kumar M, et al. Chemiosmotic and murburn explanations for aerobic respiration: Predictive capabilities, structure-function correlations and chemico-physical logic. Arch Biochem Biophys 2019; 676: 108128. [DOI: 10.1016/j.abb.2019.108128]

5. Manoj KM. Torday's prognosis for aging and mortality: more evolution and better life! Biomed Rev 2019; 30: 2324. [DOI: $10.14748 / \mathrm{bmr} . v 30.6384]$

6. Jacob VD, Manoj KM. Are adipocytes and ROS mistaken for villains, or are they protagonists in the drama of life? The murburn perspective. Adipobiology 2019; 10: 7-16. [DOI: $10.1515 / \mathrm{bmc}-2020-0002$ ] 
7. Manoj KM, Soman V. Classical and murburn explanations for acute toxicity of cyanide in aerobic respiration: A personal perspective. Toxicology 2020; 432: 152369. [DOI: 10.1016/j.tox.2020.152369]

8. Wallace K. Challenging the current paradigm of the chemiosmotic theory for cyanide toxicity. Toxicology 2020; 432: 152377. [DOI: 10.1016/j.tox.2020.152377]

9. Manoj KM. Refutation of the cation-centric torsional ATP synthesis model and advocating murburn scheme for mitochondrial oxidative phosphorylation. Biophy Chem 2020; 257: 106278. [DOI: 10.1016/j.bpc.2019.106278]

10. Manoj KM. Murburn concept: a paradigm shift in cellular metabolism and physiology. Biomol Concepts 2020; 11(1): 7-22. [DOI: 10.1515/bmc-2020-0002]

11. Manoj KM, Ramasamy S, Parashar A, Gideon D, Soman $\mathrm{V}$, Jacob V, et al. Acute toxicity of cyanide in aerobic respiration: Theoretical and experimental support for murburn explanation. Biomol Concepts 2020; 11: 32-56. [DOI: 10.1515/bmc-2020-0004]

12. Manoj KM. Aerobic Respiration: Criticism of the Proton-centric Explanation Involving Rotary Adenosine Triphosphate Synthesis, Chemiosmosis Principle, Proton Pumps and Electron Transport Chain. Biochemistry Insights 2018; 11: 1178626418818442. [DOI: $10.1177 / 1178626418818442]$

13. Manoj KM, Parashar A, David Jacob V, Ramasamy S. Aerobic respiration: proof of concept for the oxygen-centric murburn perspective. J Biomol Struct Dyn 2019; 37(17): 4542-4556. [DOI: 10.1080/07391102.2018.1552896]

14. Gideon D, Jacob V, Manoj KM. Murburn concept heralds a new era in cellular bioenergetics. Biomed Rev 2019; 30: 89-98. [DOI: 10.14748/bmr.v30.6390]

15. Manoj KM. Debunking Chemiosmosis and Proposing Murburn Concept as the Operative Principle for Cellular Respiration. Biomed Rev 2017; 28: 31-48. [DOI: 10.14748/bmr.v28.4450]

16. Bazhin N. The essence of ATP coupling. ISRN Biochemistry 2012; 2012: 827604. [DOI: 10.5402/2012/827604]

17. Bazhin N. Proton gradient energy in the catalytic ATP synthesis. Reaction Kinetics and Catalysis Letters 2007; 90: 401-404. [DOI: 10.1007/s11144-007-5113-5]

18. Manoj KM, Bazhin NM. Murburn precepts of aerobic respiration. OSF Preprints 2020. [DOI: 10.31219/osf.io/ $\mathrm{hx} 4 \mathrm{p} 9$ ]

19. Manoj KM, Bazhin NM, Parashar A, Gideon DA, Jacob VD, Haarith D, et al. Murburn precepts for the light re- action of oxygenic photosynthesis. OSF Preprints 2020. [DOI: 10.31219/osf.io/95brg]

20. Slater EC. An Evaluation of the Mitchell Hypothesis of Chemiosmotic Coupling in Oxidative and Photosynthetic Phosphorylation. European Journal of Biochemistry 1967; 1(3): 317-326. [DOI: 10.1111/j.1432-1033.1967. tb00076.x]

21. Slater EC. The mechanism of the conservation of energy of biological oxidations. Eur J Biochem 1987; 166(3): 489-504. [DOI: $10.1111 / j .1432-1033.1987 . t b 13542 . x]$

22. Williams RJP. Some unrealistic assumptions in the theory of chemi-osmosis and their consequences. FEBS Letters 1979; 102(1): 126-132. [DOI: 10.1016/00145793(79)80943-6]

23. Chance B, Mela L. A hydrogen ion concentration gradient in a mitochondrial membrane. Nature 1966; 212(5060): 369-372. [DOI: 10.1038/212369a0]

24. Chance B, Mela L. Proton movements in mitochondrial membranes. Nature 1966; 212(5060): 372-376. [DOI: $10.1038 / 212372 \mathrm{a} 0]$

25. Ling GN. Oxidative phosphorylation and mitochondrial physiology: a critical review of chemiosmotic theory, and reinterpretation by the association-induction hypothesis. Physiol Chem Phys 1981; 13(1): 29-96.

26. Wainio WW: An Assessment of the Chemiosmotic Hypothesis of Mitochondrial Energy Transduction. In: Bourne GH, Danielli JF, Jeon KW, eds. Int Rev Cytol. Volume 96: Academic Press, 1985; 29-50.

27. Nałecz MJ. Is there sufficient experimental evidence to consider the mitochondrial cytochrome bc1 complex a proton pump? Probably no. J Bioenerg Biomembr 1986; 18(1): 21-38. [DOI: 10.1007/bf00743610]

28. Berden J. Rotary Movements within the ATP Synthase do not Constitute an Obligatory Element of the Catalytic Mechanism. IUBMB Life 2003; 55(8): 473-481. [DOI: 10.1080/15216540310001612318]

29. Lee CP, Gu Q, Xiong Y, Mitchell RA, Ernster L. P/O ratios reassessed: mitochondrial $\mathrm{P} / \mathrm{O}$ ratios consistently exceed 1.5 with succinate and 2.5 with NAD-linked substrates. FASEB $J$ 1996; 10(2): 345-350. [DOI: 10.1096/ fasebj.10.2.8641569]

30. Mitchell P. Keilin's respiratory chain concept and its chemiosmotic consequences. Science 1979; 206(4423): 1148-1159. [DOI: 10.1126/science.388618]

31. Boyer PD. Energy, Life, and ATP. Bioscience Reports 1998; 18(3): 97-117. [DOI: 10.1023/A:1020188311092] 
32. Dmitriev LF. [Mechanism of coupling of oxidation and phosphorylation]. Mol Biol (Mosk) 1986; 20(4): 11111125.

33. Schole J, Schole C. "Radical theory" of oxidative phosphorylation and photophosphorylation. J Theor Biol 1994; 169(2): 197-207. [DOI: 10.1006/jtbi.1994.1141]

34. Kasumov EA, Kasumov RE, Kasumova IV. A mechanochemiosmotic model for the coupling of electron and proton transfer to ATP synthesis in energy-transforming membranes: a personal perspective. Photosynth Res 2015; 123(1): 1-22. [DOI: 10.1007/s11120-014-0043-3]

35. Manoj KM, Hager LP. Utilization of peroxide and its relevance in oxygen insertion reactions catalyzed by chloroperoxidase. Biochim Biophys Acta 2001; 1547(2): 408-417. [DOI: 10.1016/S0167-4838(01)00210-2]

36. Manoj KM. Chlorinations catalyzed by chloroperoxidase occur via diffusible intermediate(s) and the reaction components play multiple roles in the overall process. Biochim Biophys Acta 2006; 1764(8): 1325-1339. [DOI: https:// doi.org/10.1016/j.bbapap.2006.05.012]

37. Manoj KM, Hager LP. Chloroperoxidase, a Janus Enzyme. Biochemistry 2008; 47(9): 2997-3003. [DOI: 10.1021/ bi7022656]

38. Manoj KM, Baburaj A, Ephraim B, Pappachan F, Maviliparambathu $\mathrm{P}, \mathrm{k}$ v U, et al. Explaining the Atypical Reaction Profiles of Heme Enzymes with a Novel Mechanistic Hypothesis and Kinetic Treatment. PloS one 2010; 5: e10601. [DOI: 10.1371/journal.pone.0010601]

39. Manoj KM, Gade SK, Mathew L. Cytochrome P450 reductase: a harbinger of diffusible reduced oxygen species. PLoS One 2010; 5(10): e13272. [DOI: 10.1371/journal. pone.0013272]

40. Gideon DA, Hager L, Manoj KM. The intriguing enhancement of chloroperoxidase mediated one-electron oxidations by azide, a known active-site ligand. Biochem Biophys Res Commun 2011; 415(4): 646-649. [DOI: https://doi.org/10.1016/j.bbrc.2011.10.128]

41. Parashar A, Manoj KM. Traces of certain drug molecules can enhance heme-enzyme catalytic outcomes. Biochem Biophys Res Commun 2012; 417(3): 1041-1045. [DOI: 10.1016/j.bbrc.2011.12.090]

42. Gade SK, Bhattacharya S, Manoj KM. Redox active molecules cytochrome $\mathrm{c}$ and vitamin $\mathrm{C}$ enhance heme-enzyme peroxidations by serving as non-specific agents for redox relay. Biochem Biophys Res Commun 2012; 419(2): 211214. [DOI: 10.1016/j.bbrc.2012.01.149]

43. Parashar A, Venkatachalam A, Gideon DA, Manoj
KM. Cyanide does more to inhibit heme enzymes, than merely serving as an active-site ligand. Biochem Biophys Res Commun 2014; 455(3): 190-193. [DOI: 10.1016/j. bbrc.2014.10.137]

44. Manoj KM, Parashar A, Venkatachalam A, Goyal S, Satyalipsu, Singh PG, et al. Atypical profiles and modulations of heme-enzymes catalyzed outcomes by low amounts of diverse additives suggest diffusible radicals' obligatory involvement in such redox reactions. Biochimie 2016; 125: 91-111. [DOI: 10.1016/j.biochi.2016.03.003]

45. Manoj KM, Gade SK, Venkatachalam A, Gideon DA. Electron transfer amongst flavo- and hemo-proteins: diffusible species effect the relay processes, not protein-protein binding. RSC Advances 2016; 6(29): 24121-24129. [DOI: 10.1039/C5RA26122H]

46. Gideon DA, Kumari R, Lynn AM, Manoj KM. What is the Functional Role of N-terminal Transmembrane Helices in the Metabolism Mediated by Liver Microsomal Cytochrome P450 and its Reductase? Cell Biochem Biophys 2012; 63: 35-45. [DOI: 10.1007/s12013-012-9339-0]

47. Parashar A, Gade SK, Potnuru M, Madhavan N, Manoj KM. The curious case of benzbromarone: insight into super-inhibition of cytochrome P450. PLoS One 2014; 9(3): e89967. [DOI: 10.1371/journal.pone.0089967]

48. Manoj KM, et al. Metabolism of xenobiotics by cytochrome P450: novel insights into the thermodynamics, kinetics and roles of redox proteins and diffusible reactive species. In: ISSX; 2016. p. 41-42.

49. Venkatachalam A, Parashar A, Manoj KM. Functioning of drug-metabolizing microsomal cytochrome P450s: In silico probing of proteins suggests that the distal heme 'active site' pocket plays a relatively 'passive role' in some enzyme-substrate interactions. In Silico Pharmacology 2016; 4(1): 2. [DOI: 10.1186/s40203-016-0016-7]

50. Manoj KM, Parashar A, Gade SK, Venkatachalam A. Functioning of Microsomal Cytochrome P450s: Murburn Concept Explains the Metabolism of Xenobiotics in Hepatocytes. Frontiers in pharmacology 2016; 7: 161161. [DOI: 10.3389/fphar.2016.00161]

51. Parashar A, Gideon DA, Manoj KM. Murburn Concept: A Molecular Explanation for Hormetic and Idiosyncratic Dose Responses. Dose Response 2018; 16(2): 1559325818774421. [DOI: 10.1177/1559325818774421]

52. Manoj KM. Oxygenic photosynthesis: Critiquing the standing explanations and proposing explorative solutions based in murburn concept. OSF Preprints 2019. [DOI: 10.31219/osf.io/3mzfp] 
53. Manoj KM, Gideon D, Jacob V, Haarith D, Manekkathodi A. Is Z-scheme a tenable explanation for the light reaction of oxygenic photosynthesis? OSF Preprints 2020. [DOI: 10.31219/osf.io/v6tdf]

54. Manoj KM. Critical analysis of some assumptions and observations on photolytic oxygenesis by plant cells. $O S F$ Preprints 2020. [DOI: 10.31219/osf.io/y62j5]

55. Gideon DA, Nirusimhan V, Manoj KM. Are plastocyanin and ferredoxin specific electron carriers or generic redox capacitors? Classical and murburn perspectives on two photosynthetic proteins. J Biomol Struct Dyn 2020: 1-15. [DOI: 10.1080/07391102.2020.1835715]

56. Nelson DL, Cox MC. Lehninger: Principles of Biochemistry 4th edition ed. New York: W. H. Freeman \& Co., 2004.

57. Voet D, Voet JG. Biochemistry. 4th Edition ed. Hoboken, NJ: John Wiley \& Sons, Inc, 2011.

58. Hinkle PC. P/O ratios of mitochondrial oxidative phosphorylation. Biochim Biophys Acta 2005; 1706(1): 1-11. [DOI: 10.1016/j.bbabio.2004.09.004]

59. Watt IN, Montgomery MG, Runswick MJ, Leslie AGW, Walker JE. Bioenergetic cost of making an adenosine triphosphate molecule in animal mitochondria. Proc Natl Acad Sci 2010; 107(39): 16823-16827. [DOI: 10.1073/ pnas. 1011099107]

60. Cohn M, Drysdale GR. A study with O18 of adenosine triphosphate formation in oxidative phosphorylation. $J$ Biol Chem 1955; 216(2): 831-846. [DOI: 10.1016/S00219258(19)81437-0]

61. Mironova GD. Mitochondria. Structure and functions in norm and pathology, 1971: 169-173.

62. Tyszkiewicz E, Roux E: Role of the superoxide anion (O2) and hydroxyl radical (OH.) in ATP synthesis obtained with spinach chloroplasts in darkness. In: Biggens J, ed. Progress in Photosynthesis Research. Volume 3: Martinus Nijhoff Publishers, 1987; 213-216.

63. Mailer K. Superoxide radical as electron donor for oxidative phosphorylation of ADP. Biochem Biophys Res Commun 1990; 170(1): 59-64. [DOI: 10.1016/0006-291x(90)91240-s]
64. Yahalomi D, Atkinson SD, Neuhof M, Chang ES, Philippe $\mathrm{H}$, Cartwright $\mathrm{P}$, et al. A cnidarian parasite of salmon (Myxozoa: Henneguya) lacks a mitochondrial genome. Proc Natl Acad Sci U S A 2020; 117(10): 5358-5363. [DOI: 10.1073/pnas.1909907117]

65. Manoj KM, Gideon DA, Parashar A. What is the Role of Lipid Membrane-embedded Quinones in Mitochondria and Chloroplasts? Chemiosmotic Q-cycle versus Murburn Reaction Perspective. Cell Biochem Biophys 2020. [DOI: 10.1007/s12013-020-00945-y]

66. Manoj KM, Gideon DA, Parashar A. Refuting the ideas advocated by Yuly et al. (PNAS, Sep. 2020): 'Universal free energy landscapes' and 'deterministic electron-relay circuitry' are unsustainable within membrane-embedded cytochrome b protein complexes involved in bioenergetic routines. OSF Preprints 2020. [DOI: 10.31219/osf. io/4vmct]

67. Manoj KM, Gideon D. Roles of cytochromes c and b5 in mitochondria and microsomes: Classical and murburn perspectives. OSF preprints 2020. [DOI: 10.31219/osf. io/8a6ej]

68. Manoj KM, Parashar A. Murburn precepts for cytochrome P450 mediated drug/xenobiotic metabolism. OSF Preprints 2020. [DOI: 10.31219/osf.io/97ckh]

69. Manoj KM, Manekkathodi A. Light's interaction with pigments in chloroplasts: The murburn perspective. $J$ Photochem Photobiol 2020; 100015. [DOI: 10.1016/j. jpap.2020.100015]

70. Manoj KM, Jacob VD, Gideon DA, Parashar A, Haarith D, Manekkathodi A. Role of thylakoid membranes in oxygenic photosynthesis: A comparative perspective using murburn concept. OSF Preprints 2020. [DOI: 10.31219/ osf.io/8p2sx]

71. Manoj KM, Tamagawa H. A critical appraisal on cellular homeostasis, transduction of environmental stimuli and the elicitation of electrophysiological responses. $O S F$ Preprints 2020. [DOI: 10.31219/osf.io/e2ynk]

72. Manoj KM, Jacob VD. The murburn precepts for photoreception. Biomed Rev 2020. [DOI: 10.31219/osf.io/gmd5t] 